\title{
The Bully Pulpit, Social Media, and Public Opinion: A Big Data Approach
}

\section{Gabriel Michael \& Colin Agur}

To cite this article: Gabriel Michael \& Colin Agur (2018) The Bully Pulpit, Social Media, and Public Opinion: A Big Data Approach, Journal of Information Technology \& Politics, 15:3, 262-277, DOI: 10.1080/19331681.2018.1485604

To link to this article: https://doi.org/10.1080/19331681.2018.1485604

$$
\text { 册 Published online: } 05 \text { Sep } 2018 .
$$

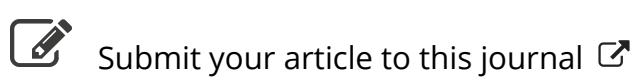

山 Article views: 36

View Crossmark data ¿ 


\title{
The Bully Pulpit, Social Media, and Public Opinion: A Big Data Approach
}

\author{
Gabriel Michael ${ }^{\mathrm{a}}$ and Colin Agur ${ }^{\mathrm{b}}$

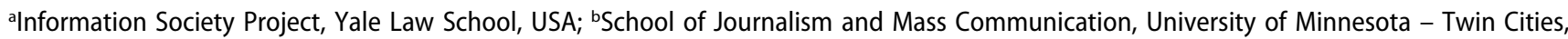 \\ USA
}

\begin{abstract}
In this paper, we seek to understand the contemporary power of the presidential "bully pulpit" the persuasive power of the nation's highest elected office-in a context of shifting patterns of mediation. We do so by examining a major social media communication platform (Twitter) for evidence of changes in public opinion before and after President Obama's high-profile statements on net neutrality in November 2014. This study includes novel and comprehensive data on the effects of a presidential announcement on public opinion. With social media playing a growing role in both electoral and policy discourse, this paper offers a methodological foundation for future studies in the changing nature of the presidential bully pulpit and the role of social media as a tool of mediation in political communication.
\end{abstract}

\section{KEYWORDS}

President; bully pulpit; social media; public opinion; twitter; machine learning big data

\section{Introduction}

In this paper, we seek to understand the contemporary power of the presidential "bully pulpit" - the persuasive power of the nation's highest elected officein a context of shifting patterns of mediation. We do so by examining a major social media communication platform (Twitter) for evidence of changes in public opinion before and after President Obama's highprofile statements on net neutrality in November 2014. Net neutrality refers to the principle that all data on the Internet should be treated in the same manner, regardless of origin, destination, content, platform, user, or other factors $(\mathrm{Wu}, 2003)$. At the time, the President's statement generated significant attention in policy, advocacy, and business communities, and was widely reported by traditional media (Hiltzik, 2014; Jackson, 2014; Nagesh, 2014). The FCCs request for public comments on net neutrality generated nearly 4 million responses, a record for the agency. We chose to examine the topic of net neutrality because it was and is substantively important, and because it offered us the opportunity to analyze presidential communications taking place through social media outside of an election cycle, and unusually, dealing with a regulatory matter normally handled by an independent agency.
This study includes novel and comprehensive data on the effects of a presidential announcement on public opinion. ${ }^{1}$ As the 2016 U.S. election and subsequent developments indicate, politicians' use of social media will continue playing a critical role in the electoral cycle as well as the day to day business of governing. This paper offers a methodological foundation for future studies on the changing nature of the presidential bully pulpit and the role of social media as a tool of mediation in political communication.

Our study makes three contributions: it offers an examination of presidential communication through social media as a component of governance, thus adding to a literature that has to date largely focused on elections. It employs open-source machine learning tools in the context of a quasi-experimental interrupted time-series research design with a control dataset, and thereby offers a strong methodological foundation for future studies. And it provides the first scholarly examination of a social media dataset to understand and theorize the presidential bully pulpit. In these ways, this study brings a new big data approach - in the form of a rigorous analysis of social media-to old questions about the communicative power of the presidency in American politics. 
We see this project as a timely opportunity to discuss two interrelated phenomena: the institutionalization of social media as a part of American political discourse, and a presidential administration's efforts to transfer the power of the presidential bully pulpit onto social media platforms. The 2016 presidential campaign has shown that Twitter in particular has become a major source of news, and a platform on which candidates can set an agenda for public discourse. Our project aims not only to empirically measure the communicative power of the presidency on social media, but also to advance a new theoretical model of the bully pulpit in a context of mass social media usage. Accordingly, this study will answer the following research questions:

(1) What effects did President Obama's November 2014 announcement on net neutrality have on the ensuing Twitter debate on this issue?

(2) What capacities and limitations do we ascribe to the bully pulpit in the context of Twitter debates on domestic political issues?

For our first research question, we hypothesize that the main effects of President Obama's announcement were to set the agenda of public debate by drawing significant additional attention to net neutrality and to portray the issue as a common-sense matter of preserving an open Internet. For our second question, we hypothesize that on Twitter, the president enjoys advantages in setting the political agenda, but that the sheer number of participants limit the President's ability to shape the debate post-announcement. Furthermore, as with other forms of media, presidential interventions often catalyze political opposition.

\section{Theory and literature}

The concept of the bully pulpit dates back to Theodore Roosevelt's time and emphasizes the role of communication technology in presidential power. In Roosevelt's time, the president's persuasive capacity depended on mediation via print media-primarily newspapers and magazines-to communicate with mass audiences of Americans (Goodwin, 2014). As the $20^{\text {th }}$ century progressed, subsequent presidents took advantage of new, faster, and more direct communication technology. Radio offered the first real-time medium the president could use to simultaneous address millions of listeners; President Franklin Delano Roosevelt made especially successful use of the radio and used that medium to promote his public works initiatives during the Great Depression (Ryfe, 1999). Television offered a visual representation of the president and played a significant role in the personalization of presidential image and authority (Druckman, 2003). With the development of the Internet, the presidential bully pulpit has enjoyed some new aspects of direct communication, in the form of WhiteHouse.gov, party websites, and social media that allow the president (or those empowered to speak on the president's behalf) to make appeals to the public without having to rely on news organizations or individual reporters (Bimber, 2014). At the same time, the White House Press Corps, other high-profile national political reporters, and an evolving cast of online players each play roles in mediating the president's message (Chadwick, 2013).

With the arrival of social media as a tool not only of campaigns, but also of governance itself, there is a need to re-examine the communicative power of the nation's highest elected office. Today, the White House, mass media, and the public share in a widespread belief that the president can shape public opinion. Yet the results of empirical research are mixed. Edwards (2003) found little evidence of long-term changes in the public's policy preferences in response to presidential leadership. However, Wood (2007) found that presidential rhetoric can change public evaluations of the economy in the short-term, and even short-term changes can have lasting political consequences. Miles (2014) found that one of the less understood and most important aspects of presidential communication is the ability to replace troublesome issues with issues more favorable to the president and his priorities. The President's net neutrality statement expressed his desires for action by an independent government agency. On the one hand, this may support Eshbaugh-Soha's (2006) theory that the president's true audience is the bureaucracy. But if the president is able to shift public opinion, he may also seek to deploy public opinion to pressure an independent agency. 
While these studies give us starting points for discussion, they do not answer a crucial question: in a period of ubiquitous television and online news, do social media platforms like Twitter offer the president new opportunities to shape public opinion outside the context of elections?

Founded in 2006, Twitter is now a well-established social media platform, with a communicative structure that distinguishes it from legacy media and offers a different type of access and participation for political actors. Accordingly, scholars have sought to identify winners and losers in this new communicative context. Some studies have found that traditional political elites, such as politicians and journalists, benefit most from the structure of debate on Twitter (Hawthorne, Houston, \& McKinney, 2013; Mascaro \& Goggins, 2012). Other studies have found that many non-traditional actors enjoy greater success on Twitter than in legacy media (Mascaro, Black, \& Goggins, 2012). Our inquiry focuses on the communicative influence of one historically dominant political actor: the president.

Although the current literature on the use of Twitter in politics has focused largely on elections, it provides a valuable starting point for our research. We group this literature into two main bodies. The first body of literature concerns Twitter usage by politicians and parties. The 2008 presidential election inspired studies of the Obama campaign's use of Twitter to engage with volunteers (Abroms and Lefebvre, 2009) and to provide updates on the candidate's location and messaging (Solop, 2010). In the years immediately following the 2008 campaign, social media became an institutionalized part of campaigns for national, state, and local office. The arrival of social media into these campaigns prompted studies of how well candidates could use Twitter as an agenda-setting mechanism (Chi \& Yang, 2010, 2011; Golbeck, Grimes, \& Rogers, 2010). Others explored the determinants of politicians' use of Twitter (Lassen \& Brown, 2010; Peterson, 2012). In a comprehensive study of the 2010 midterm elections, Gainous and Wagner (2013) developed a typology of campaign uses of Twitter and examined the ways candidates from both major parties sought to control debate on Twitter. Also focusing on the 2010 midterms, Gulati and Williams (2010) studied factors such as financing and party affiliation as predictive elements in Twitter usage by campaigns, while Bode, Hanna, Sayre, et al. (2011) compared the style and content of Senate candidates' use of Twitter to these same candidates' uses of legacy media. Focusing on the 2011 gubernatorial elections, Hong (2013) studied candidates' use of Twitter for fundraising. In a study of Twitter usage from 2006 to 2011, Wallsten (2014) examined the frequency with which different politicians' comments on Twitter appeared in print and broadcast media. The 2012 presidential election has been the subject of a number of studies that sought to understand influence on Twitter. Conway, Kenski, and Wang (2013) studied a range of presidential primary candidates' usage and found no relationship between the volume of tweets and ultimate success. Hamby's (2013) study of journalistic uses of Twitter during the 2012 election drew not only on content analysis, but also on interviews with journalists active on Twitter. That study found that the speed of Twitter debates led to a heightened role for those (primarily political staffers and journalists) able to keep up with the conversation. In a similar interview-based study, Parmelee (2013) found that many journalists saw politicians' tweets as influential in generating and shaping stories.

A second body of literature focuses on social media usage by political activists and other public actors. The 2008 presidential campaign inspired several studies of how users responded on Twitter to the televised debates between Barack Obama and John McCain (Shamma, Kennedy, \& Churchill, 2009, 2010, 2011) and early efforts to measure Twitter sentiment (Diakopoulos \& Shamma, 2010). During the 2010 election cycle, Gainous and Wagner (2013) studied the extent and nature of American voters' use of Twitter as a source of political information. Conover, Gonçalves, Ratkiewicz, et al. (2011, 2012) studied the ways that partisan Twitter users interacted with users from another party, and the ability of users to gain influence beyond their own partisan networks. Metaxas and Mustafaraj discussed the disruptive potential of Twitter users from outside political campaigns, highlighting the role of unofficial campaign accounts in tweeting campaign messages (Metaxas \& Mustafaraj, 2012; Mustafaraj, Finn, Whitlock, et al., 2011; Mustafaraj \& Metaxas, 2010). Examining gubernatorial elections in 2011, Bekafigo and McBride (2013) found that while major candidates dominated 
many Twitter discussions, there was some evidence of greater inclusivity of non-elite viewpoints. Mascaro and Goggins (2012) studied the 2012 Republican primaries and found that during the televised debates, Twitter commentary focused mainly on candidates' on-air statements, using these remarks as the basis for discussion. Focusing on the 2012 presidential election, Rainie, Smith, Schlozman, et al. (2012) studied the growth of political participation on Twitter and found that more than a third of American Twitter users used their accounts to post political information or encourage political action by other users. Examining a series of events during the election cycle, Lin, Keegan, Margolin, et al. (2013) found that a power law developed, with a concentration of users the subject of most hashtags, mentions, replies, and retweets by other users. Studying the Obama-Romney debates, Hawthorne et al. (2013) found that political and media elites on Twitter were significantly more likely to be followed, mentioned, and re-tweeted by other users. Comparing the French and American elections of 2012, Nooralahzadeh, Arunachalam, and Chiru (2013) used keyword analysis on Twitter to measure sentiment over the course of the two countries' campaigns.

Our study draws from both research on the bully pulpit and research on the use of Twitter in politics. Ours is a study of a presidential statement on a political issue (net neutrality) and the resulting public debate of that issue. Although there are a few studies of the effects of politicians' discourse on Twitter (Hamby, 2013; Lee, 2013; Parmelee \& Bichard, 2012), this is a curiously understudied area. No study to date has explicitly examined the role of the presidential bully pulpit on social media.

Second, our focus is on social media usage outside the election cycle. As the discussion above suggests, much of the literature on social media in US politics has focused on use during campaigns. A few studies have sought to understand the significance of social media in unscheduled political events such as the debate on SOPA/PIPA (Faris, Roberts, Etling, et al., 2015; Roback \& Hemphill, 2013; Boyd, Golder, and Lotan, 2010; Smith, Rainie, Himelboim, et al., 2014), and we have found some early scholarly analysis of the recent net neutrality debate (Faris et al., 2015). But such studies are rare compared to the significant body of scholarship focused on the election cycle. Since the presidency is about not just elections, but also governance, we believe that our approach-focusing on non-election political debate on social media-makes an important addition to scholarly understanding of presidential influence on social media.

\section{Methodology}

In research designs that attempt to measure changes in public opinion and public attention on specific issues, delays between the event of interest and a poll reduce our confidence that changes can be attributed to the event (Cavari, 2013). Twitter offers a high-frequency dataset that represents a large subset of the public and offers insight into contemporary political discourse in the United States. There are over 60 million active users in the United States, collectively sending more than 100 million tweets each day. While in its early years Twitter may have been dominated by tech-savvy users, today's Twitter users frequently react to all kinds of political events and express their opinions on a wide range of issues (Mitchell \& Hitlin, 2013). This process represents a culmination of a decade of growth in social media usage by political actors (Kreiss, 2012).

Employing a quasi-experimental interrupted time-series research design, we train a machine learning model on a large dataset of tweets to analyze both the number and content of tweets before and after a presidential statement. The statement, a recorded video message about net neutrality, outlined specific policy goals and occurred on 10 November $2014 .^{2}$ We begin observing tweets one week prior to the presidential announcement, and continue observing tweets for one week following the announcement. ${ }^{3}$

We fully recognize that the Twitter user base is not representative of the American public, and measurements on Twitter may at times even be at odds with measurements of the public conducted using traditional survey methods (Crawford, 2013; Mitchell \& Hitlin, 2013). However representativeness is not necessarily a requirement for the analysis of social media (Ceron, Curini, Iacus, \& Porro, 2014). Because we seek to identify relative changes in public attention and opinion, rather than absolute levels, we do not require a representative sample; so 
long as any sample bias remained constant during our two week period of observation, even this biased sample can reveal shifts in opinion. To improve internal validity and control for potentially confounding time-dependent effects, we also observe a control series of unrelated tweets on climate change, a topic about which the president made no significant statements to the U.S. public in 2014. While the president did deliver a speech on climate change before the U.N. in September 2014, this speech was not directed at the U.S. public, and did not announce any new policy goals. At the time, climate change also ranked near the bottom of Americans' priorities for presidential action (Seth Motel, 2014).

Our methodological approach has recently been successfully used to identify changes in the sentiment of tweets surrounding the Fukushima Daiichi nuclear accident (Li et al., 2016). However, in contrast to Li et al. (2016), we rely on a widely-available open-source machine learning algorithm; as a result, we are able to report validation metrics such as classification accuracy, and also offer the potential for replication and extension of our work without the need to rely on proprietary software tools.

\section{Data collection}

We licensed complete data from the Twitter Firehose from GNIP, giving us full access to every tweet published between 3 November 2014 and 17 November 2014 that matched any of the following terms: "net neutrality," "netneutrality," "climate change," or "climatechange." In contrast to the Twitter Streaming API, which provides only a sample of published tweets, our dataset includes every single tweet matching these search terms from the selected time period, totaling over 800,000 . These terms were chosen primarily to capture topical tweets that discussed our issues of interest, as well as related hashtags. Just as we neither expect nor require the Twitter user base to be representative of the public, we neither expect nor require these search terms to accurately capture the entirety of their respective issues. ${ }^{4}$ Yet as long as the semantic use of the terms remained constant over two weeks, we expect to be able to identify meaningful relative changes in the overall volume and content of the activity on Twitter.

\section{Data cleaning and preparation}

The raw data were loaded into a relational database with a structure designed to capture the multiple one-to-many relationships for some Twitter metadata (hashtags, mentions, and URLs). We performed tokenization (splitting of tweets and user biographies into "tokens," such as words, hashtags, mentions, punctuation, and emoticons), and employed a Twitter-specific part-of-speech tagger to identify grammatical information for each token (e.g., mark a particular token as a noun, verb, adjective, mention, hashtag, etc.) (Owoputi, O'Connor, Dyer, et al., 2013). ${ }^{5}$

\section{Coding}

We initially drew a random of sample of 1,000 tweets to form the basis of a manually coded training set, but found the distribution of classes in the dataset to be heavily lopsided, with far more tweets supporting net neutrality and climate change than opposing. While these results provide useful information for a traditional sample-based statistical analysis, they present a problem for machine learning, in that a randomly sampled training set will be unlikely to contain a sufficient number of minor-class tweets to extract a broad feature set in order to accurately classify out-ofsample tweets.

Thus, for net neutrality tweets, we constructed a significantly larger training set comprising 6,000 tweets. Half of the training set was randomly sampled from the complete dataset (filtered using our original search terms to contain tweets only about net neutrality), while the remaining half was sampled from tweets containing additional selected terms that we expected to be more frequently associated with tweets opposing net neutrality. ${ }^{6}$ Formally, this approach is referred to as oversampling of the minority class and is a common technique when employing machine learning methods with imbalanced datasets (Liu, Xiaohui, Huang, \& An, 2011). ${ }^{7}$

Likewise, for climate change tweets, we constructed a training set comprising 900 tweets. $^{8}$ 300 of these tweets were randomly sampled from the complete dataset, filtered to contain tweets only about climate change. The remaining 600 
tweets were sampled from tweets containing additional selected terms that we expected to be more frequently associated with tweets expressing denial of climate change. ${ }^{9}$

During exploratory data analysis, it became apparent that we should consider more than simply the content of a tweet itself to aid in our classification decisions. Lewis, Zamith, and Hermida (2013) report that the information in user-supplied biographical details is often useful in coding tweets that by themselves might appear ambiguous. For example, consider this tweet about net neutrality drawn from the dataset:

RT @TheObamaDiary: Oooooooh, love this: ?Net Neutrality Is Obamacare For The Internet!? http:// t.co/R17lI1UuBg

By itself, the text of this tweet is ambiguous. However, the user-supplied biography of this Twitter account reads as follows:

$\mathrm{Plz}$ join me in stomping out stupid Lucky 2 witness USA moving 4 ward $21^{\text {st }}$ century liberal Pro President Obama Ex-military on paper-full $\mathrm{N}$ heart \#UniteBlue

Now the sentiment of the tweet is far less ambiguous. The user biography reveals the account to belong to a supporter of President Obama, meaning this user is likely retweeting another tweet that mocks Ted Cruz's description of net neutrality as "Obamacare for the Internet," (Senator Ted Cruz, 2014). However, if the same user's biography were to describe the user as "to the right of Attila," we might likely infer that the tweet ultimately opposed net neutrality. Again, the same tweet coming from a user whose biography states "Soy latte swilling, tree hugging web surfer" would likely give us reason to infer that the tweet ultimately supported net neutrality. ${ }^{10}$ Furthermore, although Twitter users do not normally read the biography of each user's tweet alongside the tweet, they do have substantial implicit knowledge, for example., of who they follow, who follows them, and what kind of material is likely to appear in their feeds. Following Lewis et al. (2013), we find that referring to biographies and metadata during the coding process thus affords us as much information as possible to accurately characterize the political position of a tweet.
Beyond the user biography, other tweet metadata can also prove useful in coding tweets. For example, consider the following tweet:

GOP Leaders Reject Obama's Call for New Net Neutrality Rules http://t.co/9UU3fGhvtL

This tweet is ambiguous. Does the user support this action by GOP leaders, or is the user critical of it? Furthermore, the user's biography does not resolve the ambiguity:

A common-sense guy who sees that when Corporate Money and Political Power combine to force us to do anything they want by Taxing our choices, We all Lose!

However, by examining the target of the shortened URL contained in the tweet, we find that the full URL points to Breitbart.com, a right-wing news and opinion website. Taking the text of the tweet, the biography, and the expanded URL together, we now have a strong case for classifying this tweet as opposing net neutrality.

Coders were provided with the full text of tweets, user biographies, the expanded URLs of any shortened URLs embedded in a tweet, the user's Twitter handle, the user's self-provided "real name," the user's self-provided user location, and the handles and real names of any other Twitter users mentioned in the tweet. For net neutrality tweets, coding was divided among three coders, each of whom was provided with 2,400 tweets to classify. Of these, 2,000 were randomly selected from the complete training set, and the remaining 400 were randomly selected from each other coder's set to provide a way to assess inter-coder reliability. Coders were instructed to classify each tweet as either support or opposing net neutrality; in case where support or opposition was unclear, coders marked the tweets as unclassifiable. After excluding unclassifiable tweets and duplicates, the training set comprised 5,026 unique tweets, all either marked as support or opposing net neutrality. By excluding unclassifiable tweets and including non-randomly selected tweets, our approach to developing a training set mirrors the approach used in optical character recognition tasks, where training sets comprise high-quality, low-noise samples chosen to represent the whole range of objects to be classified (Schlesinger \& Hlavac, 2013, 105-106). Avoiding incorporating a third class of 
"neutral" or unclassifiable tweets simplifies both coding and model development, but comes at the cost of misclassifying truly neutral out-of-sample tweets; we address this issue at more length in Section 4.2. Across the three coders, inter-coder reliability achieved $97.9 \%$ agreement, with a Krippendorf s alpha of 0.971.

For climate change tweets, the training set comprised 703 unique tweets after excluding unclassifiable tweets. "Tweets were coded as "support" when they explicitly or implicitly expressed belief in climate change as a real phenomenon, and as "oppose" when they explicitly or implicitly expressed disbelief in climate change, or disbelief that human activity could have any effect on the climate. $^{12}$

\section{Statistical analysis}

\section{Sampling-based approach}

Initially, we drew a simple random sample of 1,000 tweets we intended to use as a training set. Our dataset included tweets about both net neutrality and climate change, and the content of the sample was roughly evenly split between the two topics: 470 tweets about net neutrality, and 529 tweets about climate change. ${ }^{13}$ However, users' attitudes about the topics were heavily lopsided in support of net neutrality (77\%) and toward action on climate change $(86 \%)$.

The date range for our data was deliberately centered around 10 November, the day when President Obama offered his video message on net neutrality. When we examined the number of tweets grouped by day, we witnessed a large uptick in tweets on 10 November, followed by a decline over the next several days, ultimately leveling off at a higher level than before the message. This uptick was driven by a large increase in tweets about net neutrality. In contrast, the number of tweets about climate change remained more stable throughout the time interval, although the announcement of the joint U.S.-China Accord on climate change on 11 November was responsible for a modest increase on 12 November (Landler, 2014).

One of our primary research questions is if and how presidential communications on platforms such as Twitter affect public opinion. To that
Table 1. Changes in Proportions of Positive Tweets in Two Periods.

\begin{tabular}{lcc}
\hline$n=885$ & Net Neutrality & Climate Change \\
\hline Positive before Nov 10 & $93.5 \%$ & $94.0 \%$ \\
Positive after Nov 10 & $90.2 \%$ & $94.0 \%$ \\
\hline
\end{tabular}

end, we split the sample into two periods: the days before 10 November, and the days after 10 November. ${ }^{14}$ Then, we measured the proportion of positive tweets in each of the two periods, and performed a two-proportion $z$-test for equality. Table 1 reports the proportions in these two periods for both topics. ${ }^{15}$

While the proportion of positive tweets about net neutrality appears to decline in the period after 10 November, the difference is not statistically significant $(\alpha=0.05, p=1)$. The test is made less statistically reliable by small cell sizes: in the first period, there are only a total of 31 tweets about net neutrality, of which 29 are positive. As we would expect given our choice of climate change as a control series, there is no statistically significant difference between the proportions pre- and postannouncement $(\alpha=0.05, p=1){ }^{16}$

This finding provides our motivation for resorting to more complex methods like machine learning. While we could have increased our sample size with the goal of improving the statistical power of this particular difference in proportions test, machine classification provides the ability to engage in far more granular analysis; for example, if we wanted to split our sample on more than a single date (as in Figure 2), or compare proportions across different variables (e.g., grouping by tweets that mention a specific Twitter user, as in Figure 3), sample size requirements would quickly become unmanageable.

\section{Machine learning approach}

To begin, we categorized tweets into two topics (net neutrality or climate change) based on the presence of our search terms in the tweet text or associated hashtags. The same tweet could fall into both topic categories if it contained appropriate search terms.

Of the total 831,776 tweets in the dataset, 382,019 mentioned net neutrality, and 445,082 mentioned climate change; 702 tweets mentioned 
both topics. The remaining 5,376 could not be automatically categorized as being about either net neutrality or climate change. In a large majority of cases, these tweets are retweets of earlier tweets that mentioned our search terms, but during the retweeting process the search term was truncated or omitted due to exceeding the maximum tweet length. Given that these tweets account for less than $1 \%$ of the total dataset, we ignore their omission here. However, they are not omitted from either the sampling process used in selecting training sets, or from the sets provided to the classification models.

Figure 1 reports tweet volumes by day across the complete dataset. Unsurprisingly, it exhibits the same patterns we witnessed in the random sample: a swell on 10 November driven by tweets about net neutrality, followed by a decay. With this higher-frequency data, however, the decay now appears to approximate a typical exponential decay curve.

For each tweet, we construct a "bag-of-words" (BOW) meta-document comprising the tweet text and user biography filtered by relevant parts of speech and excluding common English stop words; hashtags; the domain name of all expanded URLs; and the user's Twitter handle. ${ }^{17}$ "Bag-of-words" refers to the fact that most information about word ordering and sentence structure is lost-from the machine learning algorithm's perspective, each meta-document is just a "bag of words." BOWbased models have been successfully used to classify comments submitted during regulatory consultation periods (Michael \& Mark, 2015).

We applied a standard term-frequency inverse document-frequency (TF-IDF) transformation to the document term matrix, which aims to identify information-rich words by discounting words that are very common across the entire corpus. Applying a support-vector machine (SVM) classifier trained on the 5,729 manually coded tweets from Section 3.3 to these transformed meta-documents yielded five-fold cross-validated classification accuracies of $90-91 \%$ for both classes, which are acceptable considering our upper-bound of approximately $98 \%{ }^{18}$ We found that including bigrams (counts of pairs of words, rather than just single words) as features slightly improved classification accuracy, at a cost of greatly expanded feature space; however, since our primary goal is model performance rather than interpretability, we included these bigrams.

As discussed in Section 3.3, because we opted to treat our topic as a binary classification task, we knowingly misclassify a significant number of tweets that are truly neutral in orientation. To mitigate this problem without resorting to multiclass training sets and models, we obtained the class probabilities from our classifier and marked meta-documents with low probabilities of either

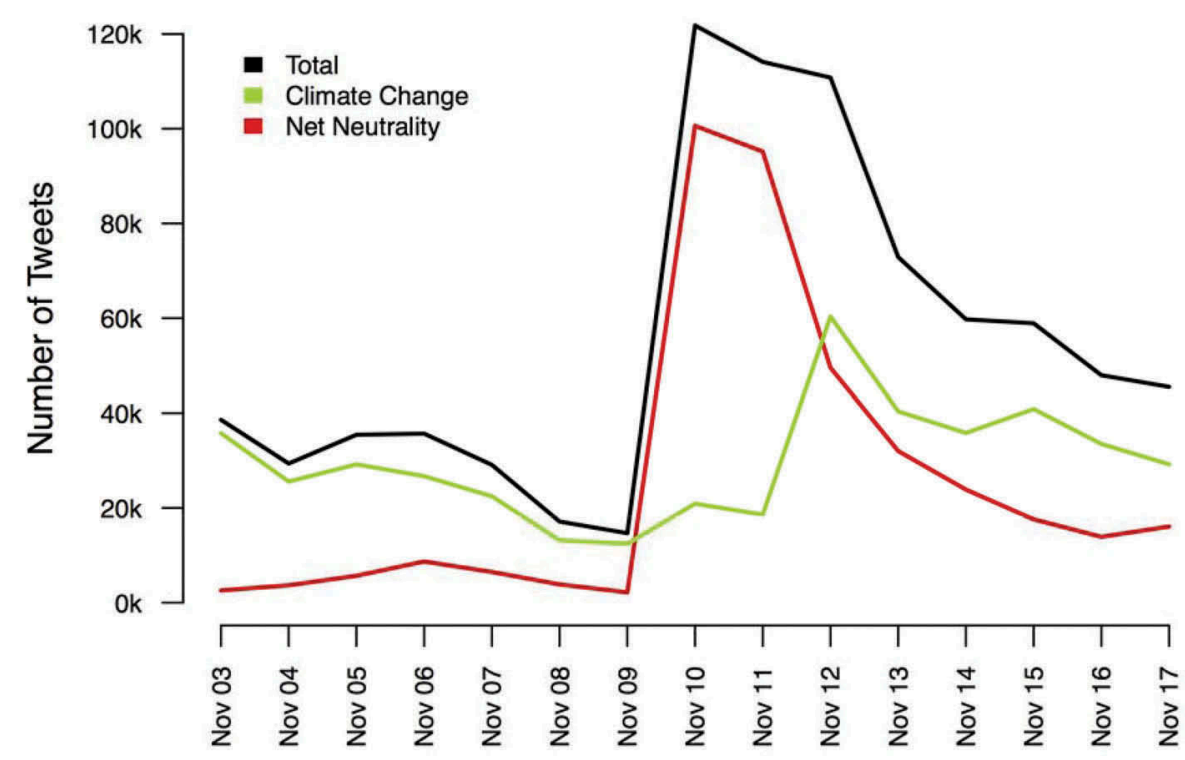

Figure 1. Number of tweets per day. 


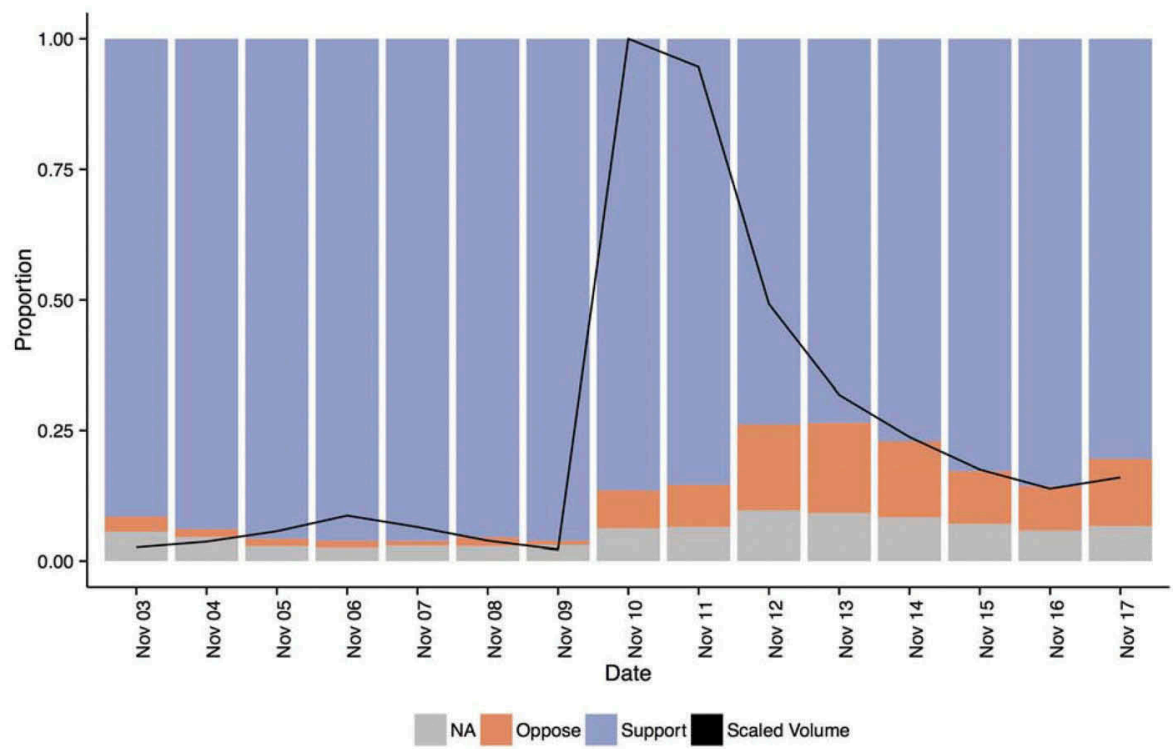

Figure 2. Proportion and volume of tweets supporting and opposing net neutrality.

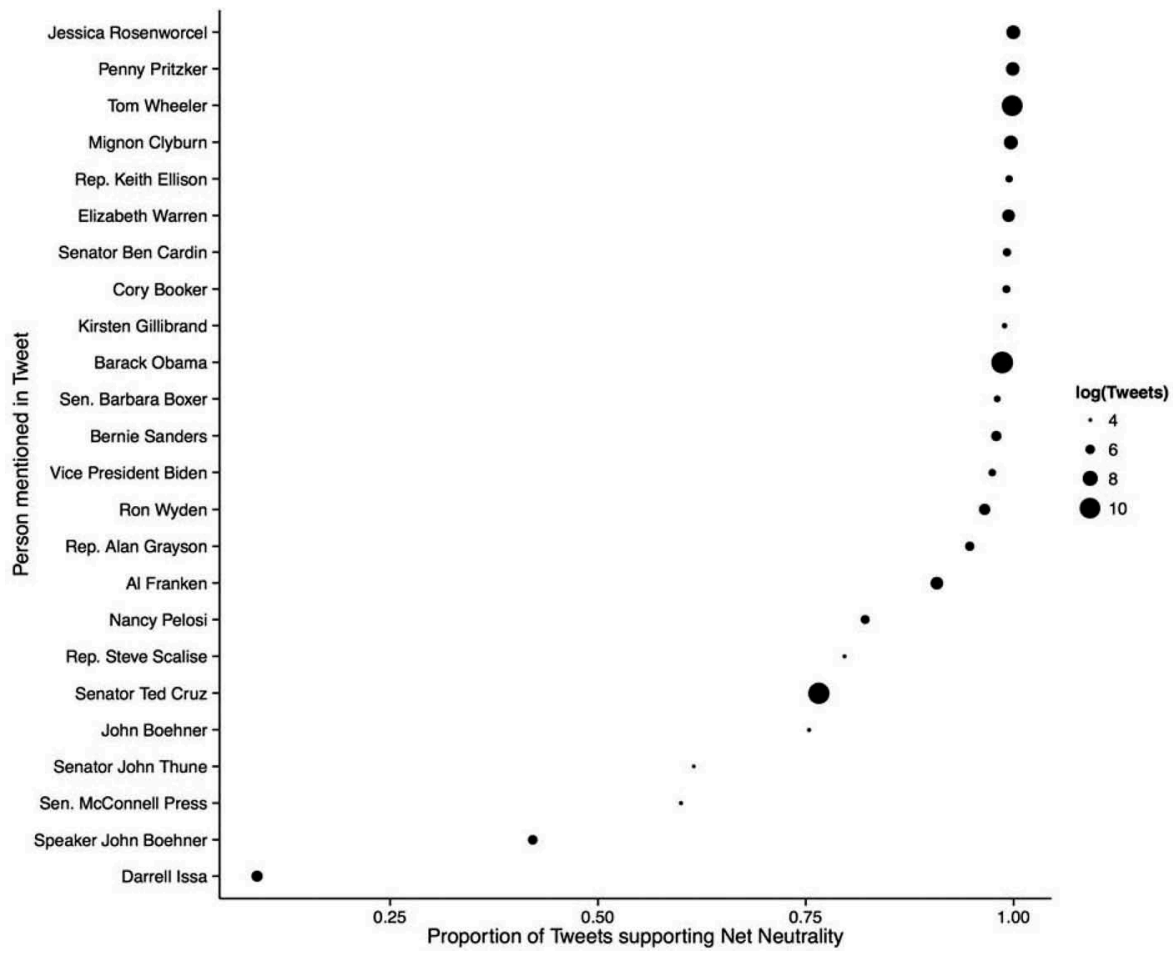

Figure 3. Members of congress and other government officials mentioned in $\geq 50$ tweets about net neutrality.

class as unclassifiable. ${ }^{19}$ This strategy amounts to discarding the classifications for difficulty-to-classify tweets, and as a result, improves classification accuracy for the remaining meta-documents. Using this strategy, we were able to improve fivefold cross-validated classification accuracy to 93-94\% for both classes while omitting fewer than $8 \%$ of tweets. $^{20}$
Table 2 reports the output of the machine classifier, indicating the percentage and volume of tweets supporting net neutrality overall, and in the pre- and post-announcement periods. Using the full dataset, we are able to precisely define pre- and post-treatment periods. The official White House Twitter account first tweeted a link to President Obama's video message on net 
Table 2. Class Composition of Tweets About Net Neutrality.

\begin{tabular}{lrrrr}
\hline$n=382,019$ & \multicolumn{2}{c}{ Pre-announcement } & \multicolumn{2}{c}{ Post-announcement } \\
\hline Support & 36,694 & $(95.6 \%)$ & 281,272 & $(81.8 \%)$ \\
Oppose & 537 & $(1.4 \%)$ & 37,244 & $(10.8 \%)$ \\
NA & 1143 & $(3.0 \%)$ & 25,129 & $(7.3 \%)$ \\
Total & 38,374 & & 343,645 & \\
\hline
\end{tabular}

neutrality at 9:20 EST (14:20 UTC) on 10 November 2014 (The White House, 2014). It is unrealistic to assume that all tweets immediately after this time truly fall into the post-announcement period. In fact, the rate of tweets about net neutrality did not exceed normal levels until a full 15 minutes after the announcement, at 9:35 EST. We chose 10:00 EST as a cutoff point for our preand post-treatment periods, and split the dataset into these two periods.

Consistent with the results from the simple random sample, the overall distribution of tweets is heavily lopsided in favor of net neutrality. This result is not necessarily surprising, given that demographic research on Twitter indicates that younger and college-educated users are overrepresented (Duggan, Ellison, Lampe, et al., 2015). We must reiterate that the representativeness of our sample is not a matter of great importance. Rather, the value of our research design becomes apparent when comparing the pre- and post-announcement percentages.

In the pre-announcement period, nearly all tweets about net neutrality are classified as supportive. In contrast, in the post-announcement period, not only does the volume of tweets increase dramatically, but the proportion of supportive tweets declines. Table 2 matches the results from the simple random sample; however, while in the random sample the difference in proportions was not statistically significant, here, the difference in proportions represents a difference in the population as a whole, making significance tests unnecessary. ${ }^{21}$ Substantively, we interpret this decline to suggest that the president's announcement not only generated substantial attention to the issue of net neutrality, but also had the effect of catalyzing opposition to net neutrality in a process driven largely by typical domestic politics.

To better convey the strong case made by our interrupted time-series research design, Figure 2 reports the proportion of tweets supporting and opposing net neutrality grouped by day, along with an indicator of overall volume. Interestingly, while overall volume (shown in the figure with a square root transformation) increases dramatically on 10 November (the day of the announcement) but then quickly declines over the following days, the proportion of tweets opposing net neutrality does not follow a similar pattern. It increases substantially on 10 November, but remains at this increased level throughout the remainder of the time series, appearing to establish a new baseline level of opposition to net neutrality.

Our use of machine classification on a large dataset of tweets facilitates additional analysis that would be infeasible using a traditional sample-based approach. For example, tweets frequently "mention" users by their Twitter usernames. These mentions were provided as metadata in our dataset, allowing us to easily compile information about which users were mentioned most often, and in what kinds of tweets. Figure 3 show the proportion of tweets supporting net neutrality and mentioning any member of Congress (including the Vice President), the President, an FCC commissioner, or the Secretary of Commerce who was mentioned in 50 or more tweets about net neutrality. ${ }^{22}$ In this dot plot, the size of the dots is scaled as a log transform of the total number of tweets mentioning the user, such that larger dots indicate many more tweets mentioning a given user.

Notably, almost all of these politicians received mentions in tweets supporting net neutrality far more often than in tweets opposing net neutrality. This is true even for Republican members of Congress who are publicly opposed to net neutrality, such as John Boehner, Mitch McConnell, John Thune, and Ted Cruz. ${ }^{23}$ One notable exception is Darrell Issa, who tweeted a number of remarks opposing net neutrality that were then widely retweeted by others.

\section{Controlling for external events}

In theory, the differences in proportion observed for the net neutrality tweets could have been driven by some other unobserved factor besides the president's announcement. In order to control for 
this possibility, we observed a series of tweets about an unrelated issue: climate change. If an unobserved factor was influencing Twitter discourse as a whole during this time period, we ought to be able to observe some kind of effect in this control series.

Tweets about climate change were classified in the same manner as those about net neutrality. As before, we obtained the class probabilities from our classifier and marked meta-documents with low probabilities of either class as unclassifiable. Using this strategy, we were able to achieve fivefold cross-validated classification accuracy of 93-94\% while omitting fewer than $6 \%$ of tweets.

Table 3 reports the output of the machine classifier, indicating the percentage and volume of tweets supporting climate change overall, and in the pre- and post-net neutrality announcement periods. Consistent with the results from the simple random sample, the overall distribution of tweets is heavily lopsided toward climate change "supporters."

In stark contrast to the results for net neutrality (Table 2), the proportions of tweets about climate change classified as supportive or opposing do not vary significantly in the pre-announcement and postannouncement periods. This is the expected result for the control series, and matches the results from the simple random sample. These results offer strong evidence that there were no other broad external factors unrelated to the president's announcement that could have caused the change in proportions shown in Table 2. If there were external factors that affected the political conversation on Twitter as a whole during this time period, we should have witnessed some change in the proportions of tweets about climate change, but we do not. In fact, the proportion of tweets supporting and opposing climate change vary minimally by day, although there is an increase in overall volume on 12 November corresponding to the announcement of the U.S.-China Accord on climate change (Landler, 2014).

Table 3. Class Composition of Tweets About Climate Change.

\begin{tabular}{lrrrr}
\hline$n=427,985$ & \multicolumn{2}{c}{ Pre-announcement } & \multicolumn{3}{c}{ Post-announcement } \\
\hline Support & 147,520 & $(89.1 \%)$ & 232,153 & $(88.5 \%)$ \\
Oppose & 8410 & $(5.1 \%)$ & 15,489 & $(5.9 \%)$ \\
NA & 9707 & $(5.9 \%)$ & 14,706 & $(5.6 \%)$ \\
Total & 165,637 & & 262,348 & \\
\hline
\end{tabular}

The conversation about climate change on Twitter also appears to be far more global than the conversation about net neutrality. Of the top 25 Twitter users mentioned in tweets about climate change during the period of study, more than half of the accounts belong to foreign (non-U.S.) or international organizations or persons, reflecting the relative lack of domestic political interest in climate change at the time. In contrast, not a single one of the top 25 mentioned users in our net neutrality data was a foreign or international organization or person.

\section{Conclusion}

In this paper, we have sought to understand: (a) the effects of President Obama's November 2014 announcement on net neutrality on the ensuing Twitter debate about that issue and (b) the capacities and limitations of the presidential bully pulpit in the context of Twitter debates on domestic political issues. Our findings provide answers to both of our research questions.

Our control series (data on Twitter discussions of climate change) offer strong evidence that it was the President's announcement catalyzing the changes in the net neutrality debate we observed on Twitter. We used the same model specifications over the same time period and found that for climate change, there was little variance in levels of support from pre-announcement to postannouncement. This was in sharp contrast to net neutrality, where an immediate and sustained set of changes took place, in volume of tweets, hashtags, range of participants, and level of support for net neutrality. Using our control series on climate change, we conclude that the dramatic changes in Twitter data related to net neutrality were not the result of external events or factors affecting Twitter as a whole.

Our key finding is that announcement very clearly shaped the conversation on Twitter. Within minutes of his announcement on net neutrality, and well before traditional media had reported on it, Twitter activity changed in two major ways. His intervention prompted a significant increase in the volume of tweets related to net neutrality; it also catalyzed opposition. These 
changes were visible following the president's announcement and continued in the days that followed (Figure 2). In this sense we can see both the power and limit of the President's ability to rally public opinion on Twitter. Obama succeeded in two respects: first, he brought significant additional public attention to a highly technical regulatory issue, and created a national discussion about that issue largely on the terms of his choosing (that net neutrality was a common sense matter of preserving an open Internet); and second, despite the dramatic increase in the volume of tweets, net neutrality retained an overwhelming (if somewhat reduced) proportion of participants' support. The chief limitation of the president's ability to influence the debate on Twitter was the well-organized opposition to his overall policies and priorities. A significant number of the tweets against net neutrality focused on the president himself or on the Obama administration, or on tangentially related issues, rather than net neutrality specifically.

We also found that the President sought to induce a specific policy outcome by an independent agency (the FCC) and ultimately succeeded in achieving that policy outcome. In his announcement, President Obama identified net neutrality as a major issue, initiated the discussion in terms of common carriers, named the FCC as the body responsible for telecommunications policy, and urged the FCC to adopt net neutrality policies. Here we see the presidential bully pulpit used not just to influence public opinion, but also to potentially influence decision-making at an independent regulatory agency. In the weeks and months that followed, it appears the President got his wish: as shown in Figure 3, Chairman Tom Wheeler and several other FCC commissioners were among the most frequently mentioned persons in the Twitter debate on net neutrality. Despite having offered a much weaker proposal in May 2014, by February 2015, just three months after President Obama's announcement, the FCC implemented a set of open Internet rules to protect net neutrality, rapidly bringing to a close what had been a several year policy and legal battle. This about-face is notable given that in the past, the FCC has been considered a prime example of an agency independent and powerful enough to resist presidential power (Devins, 1993).
As an extension of the presidential bully pulpit, Twitter thus has clear and measurable effects. Although the president can exert power and influence on broadcast television, this is nevertheless a highly mediated type of communication. Networks can choose if, how, and when to schedule presidential addresses, and the context of programming (what comes before and after, or what is airing simultaneously) can affect how the address is received by audiences. By contrast, Twitter gives the president and his communication team a way of communicating at a time of his choosing, on any issue, using a variety of media formats. The directness and flexibility of Twitter allows the president to bypass legacy media and release statements or news on his own terms. For these reasons, we find that Twitter has offered a large new communicative forum for the president and thus augmented the power of the bully pulpit. Although Twitter's longterm future as a dominant social media platform remains in question, whatever displaces it, it seems likely that our approach of machine-coding large amounts of textual data will prove valuable.

More broadly, the arrival of social media into American politics has led to a new mode of publicness by the president, and to a new dimension in his or her relationship with citizens. Social media platforms such as Twitter grant presidents nearly instantaneous access to large audiences without having work through traditional gatekeepers. More than that, social media offer ways to set a news agenda on legacy media. The president's use of the bully pulpit on social media platforms can even come full circle, with traditional media reporting on online scuffles. Just as evening news programs have traditionally relied on newspapers and other media published earlier in the day, now these same programs can draw on the debates-in textual and multimedia formats-that have taken place on social media. In this sense, we see the persistence of mediation in presidential discourse. Furthermore, because other political actors, such as members of Congress and federal agencies, also engage with these social media platforms, the president now has additional opportunities to commend, criticize, censure, and encourage his desired policies and messages-and to do so on a platform that allows both his supporters and detractors to reiterate or respond to the original messaging. 
Although President Obama appears to have succeeded in the net neutrality debate on Twitter, the longer-term question is how future debates will unfold. On Twitter, the president enjoys an agenda-setting capacity, and a substantive tweet from his account will generate significant discussions both on Twitter and on legacy media. What the president cannot control is what other actors will do. In the case of net neutrality, the population tweeting about the issue overwhelmingly supported President Obama's position. For future debates on Twitter, much will depend on the issue, the communicative power of the president, and the set of participants in the debate.

\section{Notes}

1. To facilitate replication and additional research, we provide a repository of computer code, as well as our manually labeled test and training sets and coding instructions, available at https://github.com/ [URL redacted for peer review].

2. The video is available at https://www.youtube.com/ watch? $\mathrm{v}=\mathrm{uKcjQPVwfDk}$.

3. While we could have obtained additional data over a longer time period, resource constraints limited the amount of data we could purchase to two weeks' worth.

4. Our search terms were also only in English.

5. A Twitter-specific part of speech tagger is necessary given that the syntax, orthography, and vocabulary of tweets differ markedly from standard English (Owoputi et al., 2013).

6. Specifically, these terms were "tcot", "govt", "control", and ("regulat" but not "regulato*"). Respectively, these terms sought to capture tweets that use the hashtag "\#tcot" ("top conservatives on Twitter"), spoke about the government, mentioned "control," and spoke about regulations but not regulators. We chose these terms on the basis of frequency analysis and domain knowledge obtained during manual coding.

7. Although our oversampling method means the training set no longer reflects a random sample of minority-class tweets, any selection bias introduced by our method would have been detected as significantly different levels of model performance on randomly sampled versus oversampled test data, which we did not observe.

8. We opted for a smaller training set for the control series both to reduce the burden of manual coding, and because we were less interested in granular analyses of the control series.
9. In this case, the terms were "skeptic," "consensus," "agw" (anthropogenic global warming, either in the tweet text or as a hashtag), "scam," "myth," "expert," "conservative" (in the tweet text), and "conservative" (in the user's biography).

10. Both of these examples are slight modifications of real user biographies. Because our outcome of interest is the proportion of published tweets support or opposing net neutrality, our classification decisions focus on the intentions of the user publishing the tweet, rather than the tweet's audience.

11. Due to time and resource constraints, we re-used a single coder from the group of three that had coded the net neutrality tweets; thus, we do not report an inter-coder reliability score.

12. In contrast to the initial coding scheme used for the original random sample of 1,000 tweets, in this training set, tweets that expressed opposition to political action on climate change were not necessarily coded "oppose"; in fact, some of these tweets were coded "support," since the expressed opposition may have exhibited a belief in climate change as a real phenomenon. Since the purpose of the coding scheme is not to establish public opinion statistics, the exact definitions are less important than their consistent application across the dataset, as this consistent application will allow the identification of any changes in proportion.

13. One tweet was unclassifiable due to truncation.

14. 10 November itself is excluded.

15. These proportions exclude neutral tweets; thus, the respective proportion of negative tweets is simply $100 \%$ minus the reported value.

16. This remains true even when splitting the periods on 11 November or 12 November, dates on which the U. S.-China Accord was announced.

17. Including features such as the domain name and user's Twitter handle allow these elements to play useful roles in the classification process.

18. SVMs map a labeled training set of data into $n$-dimensional space, where $n$ represents the number of features of an observation; then, a $n-1$ dimensional hyperplane is constructed to separate the training observations into multiple classes according to their labels. The ideal hyperplane maximizes the separation between the observations belonging to each class. New observations are mapped to this $n$-dimensional space, and classified according to which side of the hyperplane they fall on. Specifically, we used the support vector classifier available in the scikit-learn package for Python with a linear kernel and a penalty parameter $C=1$; this parameter was selected by cross-validation.

19. Specifically, if a meta-document's probability of being classified as either support or oppose fell between 30\% and $70 \%$, we marked it as unclassifiable. These thresholds were chosen to balance improvements in classification accuracy with loss of coverage of the dataset. 
20. While classification accuracy metrics can provide misleading results in the presence of imbalanced classes, recall that we oversampled from the minority class to address this issue.

21. Were one to conduct a difference in proportions test anyway, $\alpha=0.01, p<0.001$.

22. We obtained the list of congressional Twitter accounts from a public list maintained by CSPAN, and accessed via the Twitter API.

23. "John Boehner" and "Speaker John Boehner" refer to two separate accounts both maintained by John Boehner; the latter is for his communications as Speaker of the House.

\section{Funding}

This study was supported by Oscar M Ruebhausen Fund under Internal Yale Law School grant.

\section{References}

Abroms, L. C., \& Lefebvre, R. C. (2009). Obama's wired campaign: Lessons for public health communication. Journal of Health Communication, 14(5), 415-423. doi:10.1080/10810730903033000

Bekafigo, M. A., \& McBride, A. (2013). Who tweets about politics? Political participation of Twitter users during the 2011 gubernatorial elections. Social Science Computer Review, 31(5), 625-643. doi:10.1177/0894439313490405

Bimber, B. (2014). Digital media in the Obama campaigns of 2008 and 2012: Adaptation to the personalized political communication environment. Journal of Information Technology \& Politics, 11(2), 130-150.

Bode, L., Hanna, A., Sayre, B. et al. (2011) Mapping the political Twitterverse: Finding connections between political elites (Working Papers, p. 59.

Boyd, D., Golder, S., \& Lotan, G. (2010) Tweet, tweet, retweet: Conversational aspects of retweeting on Twitter. Proceedings of the 2010 43rd Hawaii International Conference on System Sciences, HICSS'10, 1-10. Washington, DC: IEEE Computer Society.

Broersma, M., \& Graham, T. (2012). Social media as beat: Tweets as a news source during the 2010 British and Dutch elections. Journalism Practice, 6(3), 403-419. doi:10.1080/ 17512786.2012.663626

Cavari, A. (2013). The short-term effect of going public. Political Research Quarterly, 66(2), 336-351. doi:10.1177/ 1065912912448931

Ceron, A., Curini, L., Iacus, S. M., \& Porro, G. (2014). Every tweet counts? How sentiment analysis of social media can improve our knowledge of citizens' political preferences with an application to Italy and France. New Media \& Society, 16(2), 340-358. doi:10.1177/1461444813480466

Chadwick, A. (2013). The hybrid media system: Politics \& power. New York, NY: Oxford University Press.
Chi, F., \& Yang, N. (2010) Twitter in congress: Outreach vs transparency. http://mpra.ub.uni-muenchen.de/24060/. 10.2139/ssrn.1630943

Chi, F., \& Yang, N. (2011). Twitter adoption in congress. Review of Network Economics, 10, 1. doi:10.2202/14469022.1255

Conover, M., Gonçalves, B., Ratkiewicz, J. et al. (2011) Predicting the political alignment of Twitter users. 2011 IEEE Third International Conference on Privacy, Security, Risk and Trust (PASSAT) and 2011 IEEE Third International Conference on Social Computing (SocialCom), 192-199.

Conover, M. D., Gonçalves, B., Flammini, A., et al. (2012). Partisan asymmetries in online political activity. EPJ Data Science, 1(1), 6. doi:10.1140/epjds6

Conway, B. A., Kenski, K., \& Wang, D. (2013). Twitter use by presidential primary candidates during the 2012 campaign. American Behavioral Scientist, 57(11), 1596-1610. doi:10.1177/0002764213489014

Crawford, K. (2013) The hidden biases in big data. Harvard Business Review https://hbr.org/2013/04/the-hiddenbiases-in-big-data.

Devins, N. (1993). Political will and the unitary executive: What makes an independent agency independent. Cardozo Law Review, 15, 273.

Diakopoulos, N. A., \& Shamma, D. A. (2010) Characterizing debate performance via aggregated twitter sentiment. Proceedings of the SIGCHI Conference on Human Factors in Computing Systems, CHI'10, 1195-1198. New York, NY: ACM.

Druckman, J. N. (2003). The power of television images: The first Kennedy-Nixon debate revisited. Journal of Politics, 65, 559-571. doi:10.1111/1468-2508.t01-1-00015

Duggan, M., Ellison, N. B., Lampe, C. et al. (2015) Demographics of key social networking platforms. http:// www.pewinternet.org/2015/01/09/demographics-of-keysocial-networking-platforms-2/.

Edwards, G. C. (2003). On deaf ears: The limits of the bully pulpit. New Haven, CT: Yale University Press.

Eshbaugh-Soha, M. (2006). The president's speeches: Beyond "going public". Boulder, CO: Rienner.

Faris, R., Roberts, H., Etling, B. et al. (2015). Score another one for the internet? The role of the networked public sphere in the US net neutrality policy debate. In The role of the networked public sphere in the US net neutrality policy debate (February 10, 2015). Berkman Center Research Publication.

Gainous, J., \& Wagner, K. M. (2013). Tweeting to power: The social media revolution in American politics (1st ed.). New York, NY: Oxford University Press.

Golbeck, J., Grimes, J. M., \& Rogers, A. (2010). Twitter use by the U.S. congress. Journal of the American Society for Information Science and Technology, 61(8), 1612-1621. doi:10.1002/asi.21217

Goodwin, D. K. (2014). The Bully Pulpit: Theodore Roosevelt, William Howard Taft and the Golden Age of American journalism. New York, NY: Simon \& Schuster. 
Groshek, J., \& Al-Rawi, A. (2013). Public sentiment and critical framing in social media content during the 2012 U.S. presidential campaign. Social Science Computer Review, 31(5), 563-576. doi:10.1177/0894439313490401

Gulati, J., \& Williams, C. B. (2010). Communicating with constituents in 140 characters or less: Twitter and the diffusion of technology innovation in the United States congress. Available at SSRN 1628247. doi:10.2139/ ssrn. 1628247

Hamby, P. (2013) Did Twitter kill the boys on the bus? Searching for a better way to cover a campaign. http:// shorensteincenter.org/d80-hamby/.

Hawthorne, J., Houston, J. B., \& McKinney, M. S. (2013). Live-tweeting a presidential primary debate exploring new political conversations. Social Science Computer Review, 31 (5), 552-562. doi:10.1177/0894439313490643

Hong, S. (2013). Who benefits from twitter? Social media and political competition in the U.S. house of representatives. Government Information Quarterly, 30(4), 464-472. doi:10.1016/j.giq.2013.05.009

Kim, M., \& Park, H. W. (2012). Measuring Twitter-based political participation and deliberation in the South Korean context by using social network and triple helix indicators. Scientometrics, 90(1), 121-140. doi:10.1007/ s11192-011-0508-5

Kreiss, D. (2012). Taking our country back: The crafting of networked politics from Howard Dean to Barack Obama 1st ed. New York: Oxford University Press.

Landler, M. (2014) U.S. and China reach climate accord after months of talks. The New York Times http://www.nytimes. com/2014/11/12/world/asia/china-us-xi-obama-apec.html.

Lassen, D. S., \& Brown, A. R. (2010). Twitter: The electoral connection?. Social Science Computer Review, 0894439310382749.

Lee, E. J. (2013). Effectiveness of politicians' soft campaign on Twitter versus TV: Cognitive and experiential routes. Journal of Communication, 63(5), 953-974.

Lee, E. J., \& Oh, S. Y. (2012). To personalize or depersonalize? When and how politicians' personalized tweets affect the public's reactions. Journal of Communication, 62(6), 932-949. doi:10.1111/j.1460-2466.2012.01681.x

Lewis, S. C., Zamith, R., \& Hermida, A. (2013). Content analysis in an era of big data: A hybrid approach to computational and manual methods. Journal of Broadcasting \& Electronic Media, 57(1), 34-52. doi:10.1080/08838151.2012.761702

Li, N., Akin, H., Su, Y. L., Brossard, D., Xenos, M., \& Scheufele, D. (2016). Tweeting disaster: An analysis of online discourse about nuclear power in the wake of the Fukushima Daiichi nuclear accident. Journal of Science Communication, 15(5), 1-20.

Lin, Y. R., Keegan, B., Margolin, D., et al. (2013). Rising tides or rising stars? Dynamics of shared attention on Twitter during media events. arXiv, 1307, 2785.

Liu, Y., Xiaohui, Y., Huang, J. X., \& An, A. (2011). Combining integrated sampling with SVM ensembles for learning from imbalanced datasets. Information
Processing \& Management, 47(4), 617-631. doi:10.1016/ j.ipm.2010.11.007

Mascaro, C., Black, A., \& Goggins, S. (2012) Tweet recall: Examining real-time civic discourse on Twitter. Proceedings of the 17th ACM international conference on supporting group work, 307-308. ACM.

Mascaro, C., \& Goggins, S. P. (2012) Twitter as virtual town square: Citizen engagement during a nationally televised Republican primary debate. SSRN Scholarly Paper ID 2108682, Social Science Research Network, Rochester, NY.

Metaxas, T., \& Mustafaraj, E. (2012) Social media and the elections http://repository.wellesley.edu/cgi/view content.cgi article $=1030 \&$ context $=$ scholarship $\quad 10.1126 /$ science. 1230456

Michael, G., \& Mark, A. (2015) A million monkeys at a million keyboards? Big data \& salient rulemakings. Presented at the 2015 American Political Science Association Annual Conference, San Francisco, CA.

Miles, M. (2014). The bully pulpit and media coverage: Power without persuasion. The International Journal of Press/ Politics, 19(1), 66-84. doi:10.1177/1940161213507608

Mitchell, A., \& Hitlin, P. (2013). Twitter reaction to events often at odds with overall public opinion. Pew Research Center. http://www.pewresearch.org/2013/03/04/twitterreaction-to-events-often-at-odds-with-overall-public-opi nion/.

Mustafaraj, E., Finn, S., Whitlock, C. et al. (2011) Vocal minority versus silent majority: Discovering the opinions of the long tail. Privacy, Security, Risk and Trust (PASSAT) and 2011 IEEE Third International Conference on Social Computing (SocialCom), 2011 IEEE Third International Conference on, 103-110. IEEE.

Mustafaraj, E., \& Metaxas, P. T. (2010) From obscurity to prominence in minutes: Political speech and real-time search http://repository.wellesley.edu/computersciencefa culty/9/.

Nooralahzadeh, F., Arunachalam, V., \& Chiru, C. (2013) 2012 presidential elections on Twitter: An analysis of how the US and French election were reflected in tweets. 2013 19th International Conference on Control Systems and Computer Science (CSCS), 240-246.

Owoputi, O., O'Connor, B., Dyer, C. et al. (2013) Improved part-of-speech tagging for online conversational text with word clusters. Proceedings of the North American Chapter of the Association for Computational Linguistics -Human Language Technologies, 380-390.

Parmelee, J. H. (2013). The agenda-building function of political tweets. New Media \& Society, 1461444813487955.

Parmelee, J. H., \& Bichard, S. L. (2012) Politics and the twitter revolution: How tweets influence the relationship between political leaders and the public. Lexington studies in political communication. Lanham, MD: Lexington Books.

Peterson, R. D. (2012). To tweet or not to tweet: Exploring the determinants of early adoption of Twitter by house members in the 111th congress. The Social Science Journal, 49(4), 430-438. doi:10.1016/j.soscij.2012.07.002 
Rainie, L., Smith, A., Schlozman, K. L. et al. (2012) Social media and political engagement. http://www.pewinternet. org/2012/10/19/social-media-and-political-engagement/.

Roback, A., \& Hemphill, L. (2013) "I'd have to vote against you": Issue campaigning via Twitter. In: Proceedings of the 2013 Conference on Computer Supported Cooperative Work Companion, CSCW'13, 259-262. New York, NY: ACM.

Ryfe, D. M. (1999). Franklin Roosevelt and the fireside chats. Journal of Communication, 49(4), 80-103. doi:10.1111/ j.1460-2466.1999.tb02818.x

Schlesinger, M. I., \& Hlavac, V. (2013). Ten lectures on statistical and structural pattern recognition. New York, NY: Springer Science \& Business Media.

Senator Ted Cruz. (2014). "Net neutrality" is obamacare for the internet; the internet should not operate at the speed of government". https://twitter.com/sentedcruz/status/ 531834493922189313.

Seth Motel (2014) Polls show most Americans believe in climate change, but give it low priority. Pew Research Center. http://www.pewresearch.org/fact-tank/2014/09/23/ most-americans-believe-in-climate-change-but-give-itlow-priority/.

Shamma, D. A., Kennedy, L., \& Churchill, E. F. (2009) Tweet the debates: Understanding community annotation of uncollected sources. Proceedings of the first SIGMM workshop on social media, 3-10. ACM.

Shamma, D. A., Kennedy, L., \& Churchill, E. F. (2010) Conversational shadows: Describing live media events using short messages. Proceedings of the fourth international AAAI conference on weblogs and social media.
Shamma, D. A., Kennedy, L., \& Churchill, E. F. (2011) Peaks and persistence: Modeling the shape of microblog conversations. Proceedings of the ACM 2011 conference on computer supported cooperative work, CSCW'11, 355-358. New York, NY: ACM.

Smith, M. A., Rainie, L., Himelboim, I. et al. (2014) Mapping Twitter topic networks: From polarized crowds to community clusters. Technical report, Pew Research Center, Washington, DC.

Solop, F. I. (2010). RT @BarackObama we just made history: Twitter and the 2008 presidential election. In J. A. Hendricks \& R. E. Denton Jr (Eds.), Communicator in chief how Barack Obama used new media technology to win the White House (pp. 37-49). Lexington Books.

Thimm, C., Einspänner, J., \& Dang-Anh, M. (2012). Twitter als wahlkampfmedium: Modellierung und analyse politischer social-media-nutzung. Publizistik, 57(3), 293-313. doi:10.1007/s11616-012-0156-7

Wallsten, K. (2014). Microblogging and the news: Political elites and the ultimate retweet. In J. Bishop (Ed.), Politics and policy in the information age. Hershey, PA: IGI Global.

The White House (2014) I'm urging the @FCC to keep the internet open and free. Here's my plan to protect \#netneutrality for everyone: http://go.wh.gov/net-neutrality/-bo.

Wood, B. D. (2007). The politics of economic leadership: The causes and consequences of presidential rhetoric. Princeton, NJ: Princeton University Press.

$\mathrm{Wu}$, T. (2003). Network neutrality, broadband discrimination. Journal on Telecommunications \& High Tech Law, 2, 141-176. 